\title{
Employee Empowerment in the Network Era
}

\author{
Xiaojun Fan \\ School of Accounting and Finance \\ Xi'an Peihua University \\ Xi'an, China 710125
}

\begin{abstract}
Empowerment aims to motivate employees' work enthusiasm and creativity through the sharing of information, choices and resources, and to improve the dynamic adaptability between employee and organizational performance and organization. Based on combing the related literature, the article analyzes the motivation of empowerment and enhances the empowerment effect through organizational structure reform, improvement of leadership style, stimulating employee motivation and building enterprise empowerment culture.
\end{abstract}

Keywords-employee empowerment; structure empowerment; leadership empowerment; motivation analysis

\section{INTRODUCTION}

With the increasingly complex business environment and the flattening of the organizational structure, the new generation of knowledge workers has increasingly become the main body of employees, and human resources have become an important resource for enterprises to gain competitive advantage. How to tap and exert the advantages of human resources is particularly important. This requires managers to fully understand the needs of subordinates, establish decentralized decision-making mechanisms and systems in enterprises, remove the restrictions of bureaucracy within the organization, and give employees more decision-making power and autonomy to highlight the importance of employee work. Reinventing the company's mechanism, encouraging employees to participate in decision-making, empowering employees, motivating employees to continue learning and innovating, and giving full play to their talents and intelligence will help the enterprise win competitive advantage.

\section{LITERATURE REVIEW}

Empowerment research began in the 1980s. Based on the full trust of employees, empowerment is the management process that creates opportunities for employees to learn and grow through the sharing of organizational information, decision-making power, choice rights, profits and other resources, and influences employees' motivations, attitudes and behaviors through psychological perception [1]. At present, the research and practice of empowerment mainly focuses on the empowerment of employees and customers.

Employee empowerment aims to emphasize that the organization should properly decentralize, give employees more autonomy, and conduct in-depth research on structural empowerment, leadership empowerment and psychological empowerment. The structural empowerment aims to establish a complete employee empowerment mechanism and system, ensure the sharing of power within the organizational system, and enable employees to obtain relevant information, opportunities and other resources for organizational decision to participate in management. Leadership empowerment aims to transform the leadership role in the organization and delegate more decision-making power to subordinates. The leader plays the role of supervisor and referee, and is also a counselor, through whose training of subordinates, the overall quality and performance of employees will be improved. Psychological empowerment, which focuses on the study of psychological mechanisms, refers to the control, influence and work value that employees feel during their work. It enhances employees' initiative to increase their self-efficacy and sense of accomplishment, enhances employees' self-confidence to change their work motivation and behavior [2].

With the advent of the era of information and intelligence, the enrichment of material products and the changing of the trading position of customers, it is necessary to establish a smooth, efficient, open and continuous communication platform between enterprises and customers, to form a continuous and benign interactive relationship with each other, in order to achieve a win-win situation between the company and the customer. Customer empowerment aims to enhance the initiative of customers in a variety of ways, allowing them to participate in the company's product development, design, manufacturing and marketing activities to better meet customer needs.

\section{MOTIVATION ANALYSIS OF EMPOWERMENT}

\section{A. The Complexity of the External Environment Requires Empowerment}

With the advent of the era of intelligence and networking, the production, operation and management of enterprises are facing enormous challenges. How to better adapt to and take advantage of changes in the environment, seize opportunities, avoid risks, and cultivate the core competitiveness of enterprises is even more important. As the middle and senior managers of the company, they attach great importance to the development and maintenance of customers, but because the people who are the closest to the customers are front-line employees, it is difficult for them to perceive and feel the changes of various market factors and make the right decisions. Therefore, organizational power should be further moved down to give front-line employees more autonomy and decision-making power, so that the front-line employees who 
can hear gunfire are able to make effective decisions, and timely and effectively discover and meet new customer needs. They can empower their customers through continuous interaction, to achieve a win-win situation.

\section{B. Gaining Sustainable Competitiveness Requires Empowerment}

The rapid development of science and technology and the increasingly fierce competition in the industry require enterprises to optimize the allocation of various resources, empower employees through management innovation, and give full play to the advantages of human resources. Haier's "Ren Dan He Yi" model, Handu Group's "Team Management" and Huawei's "allowing employees who can hear the guns to make decisions", all these practices are useful explorations for companies to empower their employees in order to gain a sustainable competitive advantage.

Haier's "Ren Dan He Yi" model, through the platform transformation of the organization, turns employees in the traditional sense into entrepreneurs and partners of the enterprise, turns the corporate structure from the original pyramidal organizational structure into the inverted pyramidal organizational structure, turns the manager of the enterprise from the original manager into the current resource provider and management servant, thus building a platform for employees to innovate, start a business and investment, and stimulating employees' enthusiasm and creativity.

Handu Group builds an organizational structure based on Internet thinking to respond to rapid changes in the environment and make quick response and decision-making in a timely manner. It independently explores the platform model of "incubation + service" and establishes an ecological incubation platform centered on "team management". The team consists mainly of designers, page managers and goods managers. Based on clear rights and responsibilities, the team has absolute autonomy in the design, production and sales process, and their remuneration is calculated and distributed as a team, which fully stimulates the enthusiasm of the team members. A ream can continue to evolve into more teams, and the original team can thus enjoy $10 \%$ of its incubation team's sales for six consecutive months. Through empowerment, Handu Group created a myth of 30,000 styles a year.

In response to the challenges and opportunities that big data and artificial intelligence bring to the development of the retail industry, JD.com proposes a future-oriented, customercentric, big data-based unbounded marketing. In the context of unbounded marketing, through the participation of users, enterprises, media and brand parties, the organization and business processes are transformed based on customer needs. In this way, the power is moved down, and the project team breaks the boundaries of the department, and it finally realizes the interconnection of data, technology, products, resources and markets. Through openness, empowerment, and unbounded marketing, it achieves a win-win situation for the community of interests.

\section{Human Resource Exploration Requires Empowerment}

With the continuous development of the economy and society, employees have become the main resources for the sustainable survival and development of enterprises, especially the new generation of knowledgeable staff, who is more concerned about their career development and the realization of their own values. Kanter and Liden's research found that empowerment enhances employees' organizational commitment. When companies create opportunities for employees to participate in decision-making and provide challenging jobs, employees are fully aware of the value of themselves and their work, and their sense of accomplishment is enhanced. In return, employees will increase their commitment to the company, self-management and selfmotivation to improve performance [3-4]. If the company can not provide many opportunities for employee development, and more choices and decision-making rights based on employee characteristics to make their work more autonomous, diverse, valued and challenging, it will inevitably reduce employee job satisfaction and stability. Therefore, human resource exploration requires empowerment. By optimizing the organizational structure and processes of the enterprise, combining the maturity and management situation of employees, and intentionally cultivating and guiding employees to participate in the production and operation decisions of the enterprise, the company can improve the organizational commitment of employees, promote the realization of organizational goals, and reduce the turnover rate of employees.

The research by Laschinger and Havens, Baguley, and McBurney shows that empowerment is one of the effective means of relieving employee stress, and empowerment is inversely related to employee stress. By participating in decision-making, employees can share corporate information, finance and resources, and have a more comprehensive understanding of the current and future situation of the company, thereby reducing the pressure caused by uncertain future. It also shows that empowerment can improve employee satisfaction. The greater the empowerment, the higher the employee satisfaction is. Because empowerment enables employees to obtain support from companies, superiors, peers, and subordinates in terms of competence, information, technology, tools, and encouragement, they can better accomplish their work and realize their own value.

\section{Improving Leadership Management Efficiency Requires Empowerment}

Empowering employees is not only an incentive for employees; it also reduces the transactional work of leaders, allowing them to focus on more important tasks, thereby improving management efficiency. Through empowerment, it can create opportunities for subordinates to learn new knowledge, new skills, and enhance vocational ability, so as to cultivate and encourage subordinates to tap the potential of employees, enhance their sense of accomplishment, and optimize the employee capability structure. 


\section{EMPOWERMENT DESIGN}

\section{A. Transforming the Organizational Structure and Realizing the Flattening and Platforming of the Organization}

The traditional enterprise organization is mainly composed of a conical structure, with multiple levels, strict hierarchy, high power distance, etc. In this structure, the information transmission speed is slow, and it is easy for information filtering to cause information to be untrue, which is not conducive to communication between different levels. Many departmental walls and interest walls are prone to arise among departments, breeding bureaucracy, increasing the cost of coordination between each other, weakening the efficiency and benefit of the organization, which will affect the dynamic adaptability of the organization and the work creativity of employees. With the advent of the era of intelligence and networking, the complexity of the market environment, the diversification of employee concepts, the traditional organizational structure is bound to transform into a flattening and platforming organizational structure. By reducing organizational hierarchy, expanding management scope, and changing information flow, internal effective communication can be achieved, and the diversity of employee work, skills, and abilities can be adjusted in a timely manner according to changes in the environment. Through the transformation of organizational structure, enterprises can establish effective decentralization and empowerment mechanisms and systems, create opportunities for employees to obtain decision-making information and participate in decision-making. It also enhances employee autonomy, enables them to carry out creative work, and assumes the many challenges and risks brought about by the work, thereby achieving personal value and improving performance.

By optimizing the organizational structure to achieve the downward shift of power, the frontline employees are given more choice and decision-making power, in order to better adapt to changes in market demand. Transforming the pyramid structure into an inverted pyramid structure, transforming the management function into a service function, establishing an inter-departmental and cross-team synergy mechanism, sharing resources, technology and market, realize the sharing of resources, technology and market, and all the employees share the business risks brought about by market changes and scientific and technological progress, and it gradually forms a pattern in which all employees participate in management, share resources and benefits, and share risks. Introduce a competitive mechanism and activate organizational vitality to form a number of goal-oriented learning teams and innovative wealth-creating teams, empowering the team to realize the development of employees and the long-term success of the company.

\section{B. Improving Leadership and Achieving Leadership Empowerment}

Vechio's research shows that empowerment leadership not only helps improve employee performance and satisfaction, but also reduces employee negative resistance [5].Inclusive leadership is a new type of leadership that has received much attention in recent years. They adhere to the basic concept of people-oriented, and show strong openness, accessibility and effectiveness in the process of interaction with subordinates. They focus on the opinions and suggestions of employees, encourage employees to participate in decision-making and to innovate work ideas, methods and means at work, and to creatively solve problems. This has a positive effect on guiding and changing employees' work motivation, attitudes and behaviors [6].Therefore, leaders should change their mindsets, take the initiative to fully communicate with employees, understand and try to meet the needs of employees, encourage employees to participate in corporate management decisions, be willing to and dare to decentralize, can tolerate employees' mistakes at work, and be willing to guide their subordinates and work with them to solve the difficulties encountered in the work process.

Leadership empowerment not only requires the organization to establish corresponding empowerment mechanisms and systems, the realization of the downward movement of power within the organization, but also the transformation of the role of the leader. Leaders not only have to play the role of supervisors and referees, but also need to better play the role of counselors. Through the development of performance plans with employees, the coaching of employee performance, and the guidance of their work motivation and behavior, improve employee competency and organizational performance.

Chen Qianqian et al. (2017) have shown that leaders' information sharing and collectivism are significantly positively correlated with promotional suggestions [7]. Therefore, in the process of empowerment, leaders must not only involve employees in the formulation and implementation of decision-making, to realize power, resource sharing and development of subordinates, but also realize real authorization to employees through information sharing and enhance employees. Enhance the internal identity of employees, enhance their sense of belonging, and let them actively contribute to the development of the company. Integrate collective interests, corporate vision and employee goals, guide and help employees to identify and practice corporate vision from a macro and collective perspective. For different employees, adopt different management methods and ways, pay attention to the needs of employees, and empower employees to participate in decision-making to achieve teamwork. By cultivating and forming an advanced corporate culture, creating a learning organization, creating a relaxed and harmonious working environment, encouraging employees to self-challenge and work innovation, and providing support and guidance to all aspects of human resources, financial resources, material resources and policies to achieve common development of employees and enterprises.

\section{Inspiring Employees' Motivation and Enhancing the Effect of Empowerment}

Employees are the focus of empowerment, and they are the subjects that exert their subjective initiative and continue to create value. Therefore, leaders need to be fully aware of the importance of empowerment and be good at empowering employees. On the basis of full trust of employees, combined with the performance and willingness of employees, we 
encourage employees to participate in corporate decisionmaking and assume certain responsibilities. In the process of completing challenging work, the knowledge and skills could be updated, professionalism and the ability to solve practical difficulties could be improved. In the process of empowerment, employees should be fully aware of the trust and expectations of the company. In the process of achieving the employee's work goals, the company provides information, resources and emotional support, enhances the sense of belonging of the employees, and fully feels the importance and value of themselves and their work, and enhances self-confidence and willingness to participate in decision-making. Empowerment is inseparable from the training and development of employees. Therefore, it is necessary for enterprises to develop scientific and reasonable training plans and detailed training programs, and to carry out continuous and targeted training and development for employees in combination with post competency requirements and future development needs, thus improving the effect of authorization empowerment.

\section{Doing a Good Job in the Construction of Enterprise Empowerment, Highlighting the Status of Employees}

On the basis of clarifying the company's vision and mission, the company is committed to building a culture of empowerment and empowerment. In the aspect of institutional culture construction, through the formulation and improvement of empowerment mechanism, fault tolerance mechanism and incentive mechanism and other mechanisms, tolerate the emergence of uncertainty and failure. And combine them with enterprise compensation management and performance management, establish a corresponding performance compensation management system, guide leadership empowerment, improving the enthusiasm of employees to participate in empowerment. In the core culture construction of the enterprise, the company should give full play to the demonstration role of the core figures of the enterprise, inject the concept of people-oriented, win-win cooperation and continuous innovation for the corporate culture, highlighting the importance of people in the process of enterprise empowerment. In the end, the company enhances the empowerment effect through the construction of the empowerment culture.

\section{CONCLUSION}

In the context of the era of intelligence and networking, it is believed that empowerment will become one of the important means to stimulate employee enthusiasm and creativity, will also become an important means for enterprises to cope with environmental changes and enhance competitiveness. Through structure empowerment, the transformation of enterprise organizational structure and the innovation of management mechanisms and systems, and the shifting of decision-making power and choice rights are realized. Through leadership empowerment, we can realize the sharing of all kinds of information and resources, improve the participation of employees, and enable employees to have a more comprehensive and in-depth understanding of the current situation and future of the company, enhance their sense of belonging and emotional commitment, and then enhance employee and organization performance. These, in turn, enhance employees' self-confidence and the sense of accomplishment, and enhance the ability of employees and businesses to cope with challenges and changes, thereby nurturing and forming enterprise's core competences.

\section{REFERENCES}

[1] Hao Jinlei, Yin Meng. Sharing Economy: Empowerment,Co-creating Value and Innovation of Business Model - A Case Study Based on ZBJ.COM[J]. Commercial Research,2018(5):31-40. (in Chinese)

[2] Zhou Wenhui, Yang Miao, Wang Pengcheng, Wang Chang Empowerment, Co-creating Value and Strategic Entrepreneurship: A Longitudinal Case Study Based on Handu Group and PHNIX[J].Management Review, 2017(7): 258-272. (in Chinese)

[3] Kanter R.M.Men and women of the corporation (2nd ed.)[M].New York:Basic Books, 1993.

[4] Liden,R.C.,Wayne,S.J.\&Sparrowe,R.T.An examination of the mediating role of psychological empowerment on the relations between the job,interpersonal relationships and work outcomes[J].Journal of Applied Psychology,2000,85(3):407-416.

[5] Li Hong, Zhang Longtian, Liu Yi. A review of the frontiers of empowerment research [J]. Ergonomics, 2018(1): 60-65. (in Chinese)

[6] Zhu Yu, Qian Shuting. Frontiers Analysis and Future Prospects of the Research of Inclusive Leadership [J]. Foreign Economics \& Management, 2014(2): 55-64. (in Chinese)

[7] Chen Qianqian, Fan Yun, Zhang Xu, Yu Weina. Research on the Influence Mechanism of Leaders' Information Sharing and Collectivism on Employees' Promoting Suggestions $[\mathrm{J}]$. Chinese Journal of Management, 2017(10): 1523-1531. (in Chinese) 